\title{
Prensa y orden urbano. El devenir de las concepciones sobre la ciudad presentes en las construcciones periodísticas
}

\author{
Paola Vanesa Demarchi \\ (Universidad Nacional de Río Cuarto, Argentina)
}

Recibido: 18/3/2015

Aprobado: 4/6/2015

\begin{abstract}
RESUMEN. Este artículo trata acerca del carácter "natural" y evidente que adquieren en las sociedades modernas las construcciones discursivas sobre lo esperable y deseable para la ciudad y sobre aquellos aspectos considerados problemáticos para las normas de urbanidad convenidas. Me interesa identificar y analizar las concepciones sobre el orden urbano y las emergencias sociales que se manifiestan a lo largo del siglo XX en los tratamientos informativos de la prensa riocuartense, y cómo el clima de la época se presenta en las construcciones mediáticas y a la forma en que la práctica periodística se articula con otras prácticas que dirigen su mirada a la ciudad.
\end{abstract}

Palabras clave: orden urbano / emergencias sociales / discurso / práctica periodística

\section{Press and Urban Order. The Evolution of Conceptions of the City in Journalistic Constructions}

Summary. This article grapples with the "natural" and evident character that discursive constructions acquire in modern societies, both about what is to be expected and what is to be desired vis-à-vis a city, as well as about aspects considered as problematic for the convened norms of urbanity. We are particularly interested in identifying and analyzing conceptions about the urban order and social emergences manifested by the press during the $20^{\text {th }}$ century Río Cuarto. Therefore, this study focuses in the way in which the climate of the epoch is present in media constructions and in the way in which journalistic practice is articulated with other practices interested in the city.

KEY WORDS: urban order / social emergences / discourse / practice journalistic 


\section{Introducción}

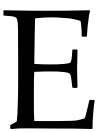
n este artículo queremos compartir algunos resultados del trabajo de investigación titulado "El devenir de las construcciones periodísticas sobre la ciudad y las emergencias sociales (siglo XX). Prensa, orden urbano y clima de época"1. En este estudio nos preocupamos por el carácter "natural" y evidente que adquieren en las sociedades modernas las construcciones discursivas sobre lo esperable y deseable para la ciudad y sobre aquellos aspectos considerados problemáticos para las normas de urbanidad convenidas. De manera particular, nuestro interés se centra en identificar y analizar las concepciones sobre el orden urbano y las emergencias sociales que se manifiestan a lo largo del siglo XX en los tratamientos informativos de la prensa riocuartense ${ }^{2}$. Partimos de la preocupación por la naturalidad de esas concepciones y sostenemos que para poder reflexionar acerca de ellas no podemos escindirlas de un particular clima de época. Así, la investigación está atenta al modo como el clima de la época se presenta en las construcciones mediá- ticas y a la forma en que el quehacer periodístico aparece articulado a un conjunto de otras prácticas que dirigen su mirada a la ciudad.

El interés de este estudio nace de investigaciones anteriores orientadas a analizar el tratamiento informativo que la prensa de la ciudad de Río Cuarto (Córdoba, Argentina) realiza sobre un sector y ambiente social y cultural que se caracteriza por ser ni típicamente urbano ni típicamente rural; condición social emergente y resultante de una diversidad de procesos de interpenetración y coexistencia de contrarios, que definimos como rurbana. Nos referimos a un sector social que habita y se traslada por la ciudad mediante formas y condiciones de vida que los hacen singulares. Carreros, cirujas, recuperadores urbanos de residuos $\mathrm{u}$ otras denominaciones se utilizan para nominarlos. Se trata de actores que resuelven su existencia mediante actividades de rebusque desarrolladas en la ciudad a través de objetos y prácticas fuertemente vinculados a lo rural. En los análisis observamos que esta condición de vida se presenta para la prensa como anacró-

1 Tesis doctoral defendida el 29 de agosto de 2014, en el marco del Programa de Doctorado en Comunicación Social de la Universidad Nacional de Rosario (Argentina).

2 La ciudad de Río Cuarto, enclavada en la región pampeana, asume la funcionalidad predominante de centro de comercio y servicios de una región en cuya economía predomina la actividad agropecuaria, en particular la agricultura y ganadería extensivas. Su ubicación geográfica y su perfil identitario (agro-ciudad) resultan importantes elementos al momento de analizar los tratamientos informativos de la prensa riocuartense. 
nica y se explica a partir de lecturas urbanas que utilizan parámetros de la modernidad para juzgarla. Las interpretaciones que se le dedican giran en torno a los sentidos de atraso y retroceso en el que se sitúa (Demarchi, 2010). De esta forma, se ofrecen tratamientos discontinuos que no van más allá de cierto "sentido común" que vincula esa condición de vida a diversas situaciones problemáticas que se ubican en un espacio de lo impensable y no deseado. Aunque estas construcciones parezcan encerrar explicaciones naturales y evidentes sobre la realidad rurbana están más bien naturalizadas en torno a ciertos principios. Pero, ¿qué es lo que ofrece aceptabilidad a estos tratamientos informativos?

Diferentes autores, entre los que destacan Foucault y Angenot, nos advierten acerca de la dificultad que reviste develar aquello que se nos presenta como una explicación natural. Aunque nos resulten evidentes, dichas concepciones responden a un sistema reglado que atraviesa las diversas construcciones discursivas de una época y se caracteriza por tendencias hegemónicas que dan cuenta de lo que se constituye como aceptable en un momento determinado.

Consideramos el campo mediático un espacio pertinente para estudiar la efectividad histórica de determinada concepción del mundo. En él podemos identificar premisas y presuposiciones que para ser aceptadas no requieren razonamiento ni argumento particu- lares, ya que su "verdad" se considera obvia, natural, eterna e indiscutible. Sin embargo, al insertarlas en el devenir de la historia son despojadas de su supuesto carácter universal e incuestionable. El trabajo pretende señalar que esas concepciones son, en cada momento, una construcción. La manera en que los medios de comunicación dan cuenta de la realidad debe incluirse dentro de un marco que contiene los saberes e ideas hegemónicos de la sociedad de cada momento. Los tratamientos, que parecen encerrar explicaciones naturales y evidentes, están estructurados en torno a ciertos principios a través de los cuales se define lo esperable.

A continuación expondremos nuestra preocupación por la apariencia de consenso que alcanzan ciertas concepciones, gracias a aquellas construcciones que tienden a mostrar que las circunstancias y sentidos que son determinados social e históricamente se presentan como naturales, universales e indiscutibles. Particularmente, nos detendremos en las concepciones sobre el espacio urbano plasmadas en la prensa gráfica y en las peculiaridades que muestra el saber que construye sobre la ciudad y los referentes del orden y del desorden. Veremos que sus construcciones operan junto a otras instituciones y saberes sobre la ciudad moderna y que su funcionamiento se encuentra movilizado por las transformaciones en las maneras dominantes de mirar. 


\section{Concepciones del orden y clima de época}

Los problemas reales que una sociedad se da como tarea resolver, no se constituyen como problemas más que en función de un imaginario central de la época o de la sociedad considerada (Castoriadis, 2007). Este conjunto de significaciones compartidas definen y estipulan lo que para una sociedad será lo normal y lo patológico, lo que tiene sentido y lo que no lo tiene, lo cuestionable y lo imposible de ser siquiera pensado. De esta manera, el orden social se presenta como algo armónicamente coordinado. En él pueden emerger experiencias sociales que constituyan una complicación para su configuración por poner en cuestión lo que para una sociedad constituye su existencia valorada, y que, por este motivo, sean definidas desde concepciones que las sitúen en el campo de lo impensable o no deseable. En este sentido, la manera en que se da cuenta de ciertas emergencias sociales se incluye dentro de un marco más general que contiene los saberes e ideas hegemónicos de la sociedad de cada momento. Nos referimos a las concepciones del mundo que en un momento y lugar determinado han conquistado eficacia práctica y una presencia natural; al clima de la época que inviste al mundo de un sentido problemático.

La noción clima de época como construcción histórico-cultural -y parte de un devenir-, nos permite referirnos a ciertas significaciones que dotan de sentido estructurado y diferenciado a la realidad y al modo en que se producen y hacen circular esos sentidos. Sin embargo, no nos referimos a una abstracción dominante que subestime el proceso histórico de cambio y conflicto y establezca entre los fenómenos simultáneos de una época una comunidad de sentido (Foucault, 2007). Nos referimos a un conjunto de regularidades epocales que otorgan sentido a diferentes discursos de una época. Decir, entonces, que tal entidad discursiva es dominante en una época no implica negar que está inserta en un juego en el que existen múltiples estrategias que la cuestionan, alterando sus elementos (Angenot, 2010). Como señala Williams (1997), lo que se define como dominante da cuenta de una interconexión y una organización más o menos adecuada de lo que de otro modo serían significados, valores y prácticas separadas e incluso dispares que el proceso activo de la hegemonía incorpora a una cultura significativa y a un orden social efectivo.

La manera en que cotidianamente se organizan y exponen los sentidos hace que ciertas visiones del mundo aparezcan como naturales e inevitables. Los medios de comunicación, por ejemplo, y como señala Stuart Hall (2010), suministran imágenes e ideas alrededor de las que la sociedad, compuesta de piezas separadas y fragmentadas, se presenta, coherentemente, como "totalidad". Así, transforman en orden el desorden del mundo (Martín Barbero, 1978). 
En nuestro estudio nos preocupamos por las construcciones de la prensa gráfica. Ellas operan dentro de una organización más amplia de instituciones y saberes sobre la ciudad moderna. Sus relatos son la prueba de la articulación del periodismo con una red de instituciones que dirigen su mirada al espacio urbano. A través de sus mecanismos de observación y registro la prensa construye un particular saber sobre la ciudad. Nos referimos a una institución atravesada por un particular ejercicio del poder y de configuración del saber que hacen posibles determinados efectos de verdad.

\section{Orden urbano y prensa gráfica}

Con el advenimiento de la modernidad las configuraciones de las concepciones del orden social se encuentran definidas a través de las objetivaciones de diversas prácticas. El orden pensado desde un marco normativo y legitimado de lo moderno clasifica lo diferente desde la carencia o incompletud. A decir de Kusch (1999), la cultura occidental se funda en dicotomías y opuestos tendientes a (re)producir un determinado ordenamiento que configurará siempre una realidad escindida, donde el opuesto, aspecto no deseado, será sistemáticamente invisibilizado.

Al pensar en la ciudad, como uno de los principales proyectos modernos, hacemos referencia a un espacio donde ciertas situaciones, actores, escenarios emergen como problemas y se interponen en el camino de la historia, del progreso, del desarrollo; situaciones calificadas de obsoletas y despachadas como tales. Situaciones que desafían la clasificación y "desmienten el buen orden de la rejilla" (Bauman, 1996, p. 91).

El conflicto que caracteriza la irrupción de ciertas emergencias sociales se explica por la síntesis unificadora de una razón a través de la que se realizan las definiciones del orden. El carácter irracional de dichas emergencias se configura a partir de aquella racionalidad dominante. Lo dominante surge del carácter hegemónico de las premisas en las que se fundamenta.

Pensamos el espacio urbano como escenario de una racionalidad dominante y en la centralidad del orden en tanto categoría fundante de aquella razón. Pero fundamentalmente, destacamos que la ciudad tiene una historia y que en este proceso ha sido definida a partir de algunos de los principales rasgos de la modernidad -Progreso, Civilización, Orden, Urbanidad, Racionalidad-, aspectos que funcionaron como argumento para clasificar y actuar sobre la realidad. Esa razón moderna -su trama de sentidos, principios, ideas- que opera moldeando la existencia del espacio urbano -clasificándolo y ordenándolo-, deja por fuera toda otra configuración que a su sentido no se ajusta. En este sentido, pensamos la modernidad como una noción histórica, cuestión que implica pensar que en diferentes estados 
de sociedad se ha recurrido a ella para definir el horizonte de lo pensable aunque solo podamos referirnos a un conjunto de regularidades epocales.

En el espacio urbano, a partir de sus continuas transformaciones y producto de su expansión, ciertos temas comenzaron a ser urgentes. Progreso y civilización fueron nociones que inspiraron una serie de medidas que mezclaban lo preventivo con lo disciplinador. Ellas quedaron plasmadas en diferentes áreas de la sociedad. Nos referimos a espacios determinantes para la producción de la verdad, en los que no solo se aspira a excluir/clasificar elementos desafiantes del orden social sino en los que se pretende fijar ciertas emergencias sociales en unos mecanismos de poder-saber e incluirlas en un sistema de normalización. En este sentido, sumamos nuestra atención en el periódico como uno de los registros más ubicuos de la ciudad, como una institución que genera un saber sobre el espacio urbano.

Las transformaciones citadinas se plasman en infinidad de documentos escritos. La prensa, por ejemplo, establece mapas de la ciudad con solo hablar de ella. En sincronía con otros discursos, hace visible sus perma- nentes mutaciones y desarrolla un saber sobre la ciudad y los referentes del orden, y del desorden. Aunque se reconozca que la ciudad suele ser su fuente de información principal, poco se revela sobre las vinculaciones de las construcciones periodísticas con un proyecto urbano mayor, sobre cómo la actividad de la prensa se liga a una serie de instituciones al momento de dar cuenta de la ciudad.

Pensamos en los medios de comunicación como un espacio táctico ${ }^{3}$ de poder en la sociedad moderna. La prensa gráfica, por ejemplo, constituye una institución valiosa al ser vehículo de proyectos, propulsora de valores, instrumento de debate y uno de los principales medios para construir ideas e imágenes de la ciudad (Alonso, 2003).

Desde su nacimiento la prensa se vinculó con el desarrollo de las ciudades, aunque solo a fines del siglo XIX la ciudad y los problemas urbanos ingresen al universo de sus principales preocupaciones. Pensamos a la prensa como un dispositivo que funciona acoplado a determinados regímenes de enunciación y visibilidad. Se trata de una institución que posibilita una particular objetivación de la realidad que se distingue por una obsesión por el orden.

3 Aunque Foucault no se dedique al estudio de los medios de comunicación, a lo largo de su desarrollo conceptual encontramos pistas que nos permiten enmarcar nuestra preocupación con relación a los medios como dispositivos de poder, como parte de esa red en la que se entrelazan diversas instituciones dentro de determinados regímenes históricos de enunciación y visibilidad. 
En nuestros contextos latinoamericanos la prensa irrumpió con fuerza con los conflictos políticos e ideológicos que rodearon la Independencia y continuó siendo a lo largo del siglo, y aun entrado el siguiente, uno de los principales ámbitos de discusión pública $\mathrm{y}$ una de las principales formas de hacer política (Alonso, 2003). Sylvia Saítta (1998) señala que las primeras décadas del siglo XX asisten al proceso de configuración de un campo específico de relaciones donde el periodismo escrito se particulariza como práctica, se separa formalmente del poder del Estado y de los partidos políticos y sienta las bases del periodismo moderno, masivo y comercial característico del siglo XX. De esta forma, deja de limitarse a los temas del Estado, de las guerras, del comercio y de los partidos políticos para conectarse al espacio urbano que pretende modernizarse y al mismo tiempo sufre los efectos de la industrialización y la urbanización acelerada. Entonces, como señala Beatriz Marocco (2002), los periódicos entran en estrecha conexión con un conjunto de instituciones con el objetivo de desarrollar un saber sobre la ciudad y los referentes del desorden. Sus objetivaciones se explican por lo que ha sido el hacer en cada momento de la historia.

La definición del orden urbanomoderno se realiza a partir de principios e ideas que operan en diferentes estados de sociedad a modos de sistemas clasificatorios de la realidad. Como estos principios resultan nociones históricas, las líneas de demarcación no son estables. A lo largo del tiempo veremos cambiar sus referentes y las maneras en que operan para dar cuenta de la realidad. A continuación expondremos algunas características de los tratamientos informativos de la prensa riocuartense en tres coyunturas particulares. A partir de su análisis reflexionaremos acerca del devenir de las construcciones periodísticas sobre la ciudad y las emergencias sociales.

\section{El devenir de las construcciones periodísticas sobre la ciudad y las emergencias sociales}

Para el análisis propuesto, el estudio se detuvo en tres momentos de la historia de la ciudad, en los que la presencia de ciertas emergencias sociales obtuvo protagonismo en las concepciones de orden urbano presentes en la prensa. La selección de las diferentes etapas por analizar se dirigió a localizar la regularidad de diferentes regímenes discursivos tras la irrupción de ciertos sucesos histórico-políticos que revelaron un conflicto entre las concepciones y prácticas de quienes se sustentan desde y para lo moderno frente a procesos emergentes en el espacio urbano, momentos en los que resulta posible identificar tensiones manifiestas en las concepciones del orden.

Los objetivos de investigación requirieron no escindir la actuación de la prensa de la de otras prácticas de la sociedad. Entonces, al insertar su discurso en el campo discursivo al que 
pertenece es posible dar cuenta de sus condiciones históricas de emergencia. Observamos que con la unidad del discurso estamos, en realidad, ante una diversidad de elementos. El discurso periodístico da cuenta de un conjunto de enunciados que provienen de diferentes campos, pero que, a pesar de todo, obedecen a reglas de funcionamiento comunes. Reglas epocales que, como señala Foucault, definen en determinado estado de sociedad de qué se puede hablar, quién puede hacerlo y cómo hacerlo.

Nuestros análisis recorren los tratamientos informativos de dos diarios que tuvieron una presencia dominante en los períodos seleccionados: El Pueblo (1912-1985) y Puntal (1980, se mantiene en la actualidad). Cada uno de estos medios se caracterizó por su permanente continuidad y por su rol protagónico en el campo mediático riocuartense. Veamos a continuación cómo se presentan las concepciones del orden en las construcciones noticiosas.

\section{a. Primera etapa (1915-1918): la ciudad vista desde la salud y la higiene}

En nuestra primera etapa el creciente proceso de urbanización fue un tema que ganó la reflexión de intelectuales, periodistas y políticos.
Al igual que muchos centros urbanos del país, Río Cuarto, a comienzos del siglo $\mathrm{XX}$, intentó la modernización y el embellecimiento de la ciudad encarando una serie de obras públicas. Una consecuencia no prevista en ese proyecto fue la profundización de las condiciones de pobreza. Asimismo, las crisis cíclicas de la economía y la difusión de enfermedades provocaron la inquietud de los dirigentes locales y de los médicos higienistas, además del crecimiento de las actividades benéficas y asistenciales.

La prensa de la época aborda las problemáticas de la sociedad desde un repertorio temático que se encontró atravesado por un conjunto de concepciones que se constituyeron hegemónicas. La salud-enfermedad, la higiene-suciedad, la idea de amenaza y contagio, la temibilidad y "mala vida" de ciertos individuos dan cuenta de la concepción del orden urbano prevaleciente. Atravesados por las ideas de infección, amenaza y contagio, mendigos, pobres y prostitutas se constituyeron en personajes peligrosos. Las preocupaciones en torno al orden urbano predominaron en un clima de confianza en el progreso y en la ciencia. La higiene y la salud constituyeron principios de cohesión del discurso social ${ }^{4}$.

Las transformaciones de la ciudad fueron interpretadas desde diferentes

4 En toda época existe una organización de lo decible, narrable y opinable que, en palabras de Angenot (2010), aseguran la división del trabajo discursivo. El autor hace referencia a 
campos del saber. Los higienistas y criminólogos, por un lado, y la iglesia, por otro, ofrecieron dos cosmovisiones que se conjugaron de manera singular en las concepciones sobre el orden urbano y las emergencias sociales. Por otra parte, del campo jurídico tradicional emergió un conjunto de tópicos que se retroalimentaron con los discursos dominantes de la época. De estos campos surgieron innumerables elementos de evaluación, muchos de los cuales quedaron plasmados en las páginas de la prensa local.

La fuerza expansiva de la legitimidad científica de la medicina permitió representar en términos médicos diferentes situaciones urbanas. Como observa Caimari (2004), el modelo del organismo se transformó en analogía natural de la sociedad y la idea de enfermedad infecciosa y contagiosa en referencia para pensar el problema urbano, las emergencias sociales. Todo ello estaba también implícito en la génesis de la criminología. Este discurso alentaba la identificación de la temibilidad de ciertas situaciones e individuos a través del hallazgo de síntomas (muchos de ellos impercep- tibles) que anunciaban la posibilidad de situaciones de peligro. Así como las infecciones afectaban al cuerpo del individuo, ciertos actores, como mendigos y prostitutas, resultaban indeseables ya que podían "infectar" la sociedad a través de su presencia patógena. Los fragmentos marginales de la sociedad fueron transformados en sectores sospechosos de albergar el germen originario que los transformaba en la "masa criminal" (Salessi, 1995 citado en Brunetti, 2006, p. 278).

En el clima de la época diversas maneras de evaluar e interpretar la complejidad creciente de la vida en la ciudad se articularon y se hicieron presentes en las páginas de la prensa, aunque con identificables dominancias discursivas. Una mirada teñida de componentes biológicos impregnó gran parte de las interpretaciones sociales sobre los procesos que se desarrollaban en la ciudad y en el seno de los sectores populares. El modelo médico, que en la sociedad del momento se focalizó en la faz higiénica de la ciudad, formó parte de las referencias para interpretar y valorar las emergencias sociales ${ }^{5}$.

una definición del discurso social en singular que implica la posibilidad de identificar en todo estado de sociedad una dominante interdiscursiva de maneras de conocer y significar lo conocido que son propias de una sociedad.

5 En la sociedad del momento, las reflexiones positivistas constituyeron la intervención discursiva más plausible para diagramar un modelo de sociedad donde las instituciones demarcan la asimilación de los sectores integrables a la modernidad. La biologización y criminalización del otro habilitó todo un repertorio de terapéuticas médicas, penales e 
Tanto el periodista como el médico se presentaron en los tratamientos informativos como actores en la ordenación de un saber sobre la ciudad. Al igual que el médico, el periodista identificó los síntomas de las enfermedades físicas y morales de ciertos actores y escenarios; y se posicionó como emisor de observación, elemento de prevención y un personaje destacado para la realización de diagnósticos.

Como los análisis de Paulina Brunetti (2006) lo muestran, las estrechas relaciones entre el discurso académico y el periodístico, acaso no dan cuenta de una relación interdiscursiva forjada en lecturas concretas sino en relatos y enunciados que circularon largamen- te en la sociedad. La perspectiva de análisis elegida nos permitió no reducir el análisis a la identificación de aquellas configuraciones que se manifestaron de manera dominante en el discurso periodístico. Las consignas de higiene y profilaxis no hubieran sido entendidas en su complejidad solo considerando las elaboraciones provenientes del campo médico-científico. Su efectividad se vio abonada por otras configuraciones que también tuvieron presencia en el discurso social, como las conformadas por el conjunto de tópicos que se difundían desde el campo benéfico-asistencial y el que provenía del campo jurídico. En este sentido, es imprescindible la consideración de las

higienistas que conformaron un "darwinismo social" de larga duración (Mallimaci, 2007, p. 100). Concepción profundamente individualista que no excluía la creencia en cierta providencia profana que operaba sobre el conjunto y regulaba los ascensos sociales según el principio de la selección natural. Desde esta providencia los sectores que fueron incapaces de transitar por el camino del progreso resultaban deleznables en un clima en el cual la convicción se halló en que el éxito era un premio merecido (Romero, 1998).

El clima de la época da cuenta de un dispositivo de intervención sobre la sociedad urbana que estuvo movilizado por la necesidad de moralizar a diferentes sectores de la ciudad. Este dispositivo conjugaba estrategias de intervención diferentes. Por un lado estuvo movilizado por un modelo organizativo propio de la medicina liberal, en el que los avances de las políticas sociales fueron incipientes y donde la atención de muchos de los problemas de la época recaía en políticas en las cuales el Estado no estaba presente de manera regular. La filantropía cobró protagonismo en este modelo. Por otra parte, el dispositivo de control orientado al espacio urbano combinó las prácticas sociales del higienismo y la criminología positivista. Hemos podido identificar la manera en que la prensa se inserta en el dilema que se produjo entre el modelo médico-asistencial y el de la caridad-beneficencia, entre la filantropía y la profilaxis.

En la época que nos ocupa, los desarrollos de la criminología y los provenientes del higienismo alcanzaron a la población como objeto de examen e interpretación instituyendo ciertas normas de acción colectiva. Muchas de las preocupaciones percibidas como amenazantes para la construcción de la ciudad moderna encontraron su explicación en esta nueva racionalidad, instaurada en una dimensión unificadora de la medicina y el progreso. 
objetivaciones de las prácticas con las que la prensa coexistió. Ellas ofrecieron diversos elementos para identificar las reglas a través de las cuales se define de qué se puede hablar, quién puede hacerlo y cómo debe hacerlo.

\section{b. Segunda etapa (1947-1951): Ia ciudad desde el discurso de la planificación urbana y el progreso}

Nos encontramos en una etapa que tiene como una de sus marcas fundamentales el pertenecer a los años del primer gobierno peronista ${ }^{6}$. La presencia del Estado es, en este momento, un dato fundamental para reflexionar sobre la complejidad que asumen las configuraciones discursivas de la prensa. Las políticas desarrolladas constituyeron un documento valioso, en el que fue posible visibilizar un modelo de sociedad que traspasó las barreras del campo político y atravesó la sociedad.

El clima de la época se nutría también de aportes que se proyectaron desde el campo científico. En los años cuarenta se observa una nueva forma de concebir el estudio de lo social ${ }^{7}$. Las teorías sociológicas enmarcadas en el funcionalismo, el estructuralismo y el abordaje sistémico ofrecieron clasificaciones, conceptos, categorías e interpretaciones que se trasladaron a los tratamientos informativos. Por otra parte, diferentes abordajes, como los comprendidos por los análisis de Alejandro Bunge (1940), y evaluaciones presentes en importantes ensayistas,

6 En la sociedad del momento hay una fuerte presencia de un discurso nacionalista. Dicho discurso presenta matices propios de los dilemas de la sociedad del momento. La ideología del Estado era nacionalista, de un acentuado estatismo. La política implementada le permitió al gobierno controlar todo el sistema económico y "subordinar la actividad privada a los objetivos establecidos desde el Estado" (Novick, 1992, p. 168). La libertad individual como la concibieron los liberales había dejado paso a esta nueva línea de pensamiento. En lo cultural predominaba el nacionalismo popular, aunque, señala Novick, en algunas áreas se observa la influencia de un nacionalismo católico conservador. El marco global de la actividad estatal lo constituye, por primera vez, la planificación económica-social centralizada (Novick, 1992, p. 172). Frente a este escenario, el diario local fue muy crítico de las medidas que tomaba el gobierno nacional. En esto jugaría su posicionamiento editorial y su alejamiento con respecto al discurso peronista. Sin embargo, las diferentes medidas tomadas por el gobierno instalaron un conjunto de tópicos y temas que circularon en un particular clima de discusiones que hizo posible el afianzamiento de ciertas concepciones del orden.

7 Alejandro Blanco (2006) señala que entre los años 1946 y 1955 la sociología experimentó un importante proceso de institucionalización. Se trató de una renovación de la ciencia social en el marco de un nuevo escenario regional e internacional en el que el desarrollo de las ciencias sociales estuvo en el primer plano de la consideración de una serie de organizaciones e instituciones consagradas a la promoción y modernización de aquellas. 
entre los que destaca Martínez Estrada (2001), ofrecieron el tono a las imágenes que se configuraron en la prensa. Constituyeron ámbitos de reflexión intelectual, llenaron de cuestionamientos a la nueva sociedad e incidieron en los abordajes periodísticos sobre las transformaciones de la ciudad. Veamos a continuación algunos ejemplos.

A mediados del siglo XX muchas ciudades argentinas sufrieron profundos cambios en su fisonomía. Estas transformaciones funcionaron para la prensa riocuartense como una imagen de la que fue difícil desvincularse al momento de brindar evaluaciones y proyecciones sobre las características de la población local.

En el contexto de un proceso de industrialización y de fuerte urbanización, la población y la planificación constituyeron temas privilegiados ligados a las ideas de progreso, modernidad, evolución y crecimiento.

La prensa recurrió a dos aspectos de la temática de la población que formaron parte de los debates de la época: el éxodo rural -y la consecuente despoblación del medio rural y superpoblación de algunas ciudades- y el crecimiento poblacional de Río Cuarto.

El proceso de industrialización constituyó una de las transformaciones más movilizadoras del momento y ubicó a la industria como factor a partir del cual dar cuenta del progreso de la ciudad. Sin embargo, en la ciudad de Río Cuarto dicho proceso no se presentó de la manera espera- da. En las discusiones mediáticas, la idea de industria (y la de ciudad industrial) aparece en una particular relación con la que del agro imperaba. En este contexto, la relación agro/ industria, en una ciudad que depende del agro, por momentos parece ser de oposición al estar asociada a dos modelos de ciudad: la ciudad industrial y la agrociudad. En las concepciones de orden urbano que se manifiestan en los tratamientos informativos el progreso de la actividad agropecuaria y el progreso de la ciudad poseen una influencia recíproca: "si al campo le va bien a la ciudad le va bien". El agro aparece asociado a sentimientos de nacionalidad, tradición y patriotismo y ubicado en una situación de desamparo frente a las políticas públicas que se implementaban.

La despoblación del medio rural se constituye, de esta forma, en un problema urbano. El abandono del campo y el crecimiento desmesurado de las grandes ciudades conllevan un desequilibrio que no resulta funcional al progreso orgánico de la ciudad, del país. La población, en una sociedad vista como un macroorganismo, daba cuenta de fenómenos de concentración y de fuertes desequilibrios que se constituían en una amenaza para las concepciones de orden del momento.

Al problema demográfico causado por el desequilibrio producto de la concentración de la población en las grandes ciudades del país, se incorporaron otras dimensiones de análi- 
sis tendientes a explicar el particular crecimiento poblacional de la ciudad, que será ahora abordado como un indicador de progreso. La población local aparece en los tratamientos informativos como una conformación abstracta. En este sentido, se describen las características de su dinámica demográfica. La prensa indica que la población está sometida a una serie de procesos y regularidades que hay que desentrañar.

El diario se introduce en el dispositivo interesado en la realización de previsiones, estimaciones estadísticas y diferentes mediciones. De esta forma, la prensa dio cuenta de ciertas regularidades de la población y de efectos propios de la agregación; de aspectos esperables y de situaciones que escapaban de la normalidad.

Para el "normal" crecimiento de la ciudad era necesario identificar los problemas que provoquen desequilibrios poblacionales. En este sentido, la escasez de viviendas y ciertas características edilicias constituyeron una emergencia social que problematizó el "normal" progreso de la ciudad.

Las emergencias sociales aparecen en el discurso de la prensa como problemas estructurales relacionados con la funcionalidad de la ciudad. En el contexto de un creciente protagonismo de las políticas públicas del Estado de Bienestar, la planificación se manifiesta como el instrumento para adecuar la expansión a un orden previsto.
A diferencia de la etapa analizada en el apartado anterior, el periodista no forma parte de una minoría ilustrada. Se presenta como un actor que mediante su actividad personifica al vecindario, al pueblo. Se trata de un enunciador movilizado por el valor de la patria, lo nacional, lo colectivo, lo justo, lo nuestro, lo local. El periodista dijo ser especialista en los fenómenos poblacionales y a partir de la reflexión sobre su devenir identificó la normalidad de su funcionamiento. La prensa riocuartense asumió un rol previsor y planificador.

En esta época, la prensa alentó un plan urbanístico "orgánico" al panorama citadino de la época. En este marco, las emergencias sociales aparecieron como problemas estructurales que hacen a la funcionalidad de la ciudad. Se trató de situaciones que se constituyeron inorgánicas para el progreso de la ciudad.

\section{c. Tercera etapa (1998-1999): una ciudad fragmentada; espacio económico y lugar de incertidumbre}

El último cuarto del siglo XX en la Argentina fue especialmente activo en términos de ideas urbanísticas. Al reflexionar sobre los mecanismos que permitieron la naturalización de las concepciones sobre el orden urbano y las emergencias sociales, identificamos que el mercado -sus mecanismos y principios de funcionamiento- fue el ámbito que ofreció las reglas de lo 
que en el momento se consideró como aceptable ${ }^{8}$. Las concepciones sobre la ciudad, en este sentido, naturalizaron una separación entre la dimensión económica y la dimensión social de la ciudad que justificó y sostuvo como esperable y deseable la identificación de sus escenarios económicamente estratégicos y el control y vigilancia de las zonas peligrosas y de los actores temibles. Esa diferenciación conllevó la consideración del ámbito económico de la ciudad como el espacio previsible, donde las reglas se basan en criterios de competitividad y eficiencia. Desde este discurso mercado-céntrico la irrupción de ciertas emergencias sociales fue valorada por su carácter imprevisible y por tanto peligroso a través de explicaciones coyunturales.

En la sociedad del momento, la ciudad constituyó un importante ámbito de reflexión académica. La implantación del modelo de desarrollo neoliberal y de procesos y mercados globales constituyeron puntos de reflexión que emergieron en los tratamientos infor- mativos que pensaban en la ciudad deseada.

La particularidad que presentó la concepción de orden urbano que se sostuvo en los tratamientos informativos de la época fue la consolidación de ciertas fisuras y la consecuente imagen de una ciudad fragmentada. En las definiciones que el diario hizo de los espacios estratégicos de Río Cuarto subyació un principio de crecimiento urbano basado en una visión dicotómica que excluyó a ciertas zonas de la ciudad. En este trabajo cobró importancia la homologación del espacio público al caos y a la inseguridad.

La ciudad, en esta doxa de mercado, se encuentra definida desde una concepción en la cual la globalización constituyó un tópico que subyació asociado a las diferentes transformaciones. Sin embargo, este tópico cambia su valoración en los tratamientos informativos que refieren a una dimensión de la ciudad que escapa de aquella imagen. Allí la globalización fue asociada a riesgos, incertidumbres e inseguridades.

8 Nos encontramos en una etapa caracterizada por la implementación del modelo de desarrollo neoliberal y por la reflexión sobre las consecuencias del fenómeno de la globalización. En el período 1998-1999 algunas de las repercusiones del modelo comenzaban a vislumbrarse de manera notoria. Estas dejaron una marca en la sociedad del momento y en las maneras de pensar las transformaciones de la ciudad.

La Argentina cambió de manera notable durante el último cuarto del siglo XX como consecuencia de las profundas transformaciones acaecidas en la economía, en la sociedad y en el campo político. Juan Suriano (2005) señala que a partir del proceso abierto en el país en 1976 se fueron abandonando las políticas que privilegiaban el pleno empleo, la demanda del mercado interno como factor del crecimiento sobre la base de la protección de la industria sustitutiva y el papel del Estado como garante del bienestar social. 
La emergencia de la inseguridad constituyó una de las problemáticas urbanas que mayor atención de la prensa concentró. Los tratamientos informativos la presentaron como resultado del crecimiento de hechos delictivos. Así, se dotó a la inseguridad de una forma, un espacio (al que definieron como las zonas vedadas) y un cuerpo concreto (que concentró a prostitutas y jóvenes). De esta forma, emerge la imagen de una sociedad fuertemente polarizada, donde el riesgo es un padecimiento de ciertos actores sociales como consecuencia de la amenazante presencia de otros.

Un sentido común punitivo instaló la necesidad de combatir la inseguridad. Esa doxa promovió el control y la vigilancia continuos y no estableció los nexos entre circunstancias sociales $\mathrm{y}$ hechos delictivos.

La pobreza fue otra emergencia social retratada por la prensa local. A tono con la dominancia que en la época obtuvo el discurso neoliberal, se desdibuja el carácter político de la problemática. Nos referimos a una particular definición reducida a términos de carencias y privaciones. La pobreza se convirtió en una categoría de clasificación a través de la cual fue posible asignar a las personas un conjunto de atributos a priori.

El discurso neoliberal fue operativo en la instalación de una concepción particular de la ciudad, donde primó el interés privado-individual. Por otra parte, los valores de la eficiencia y la competitividad lograron gran aceptabilidad en el discurso social, haciendo de la responsabilidad individual una construcción que emergió de manera presupuesta en las elaboraciones que pretendieron ofrecer respuestas a la manera de hacer frente a los problemas del momento.

Ante la emergencia de la inseguridad, fue una responsabilidad individual hacer frente a la amenaza que representaban los hechos delictivos. Fue una responsabilidad individual tanto la protección y construcción de espacios de seguridad como prevenir situaciones de peligro. La protección personal se constituyó en norma de acción y el ámbito privado emergió como espacio de seguridad.

Asimismo, ante la retórica de la responsabilidad individual las causas de las emergencias sociales se encontraron en historias personales y criterios particulares. De esta forma, la inseguridad fue abordada por una doxa penal que se encargó de sancionarla y evaluarla y la pobreza fue interpretada a partir de la consideración de competencias personales. Un criterio individualista hizo responsable al delincuente por sus actos y a los pobres por su pobreza.

En esta etapa, la efectividad de las elaboraciones del campo penal no puede ser desprendida de la dominancia del discurso mercado-céntrico, que instituyó una imagen de la ciudad fragmentada, separando la dimensión económica de la ciudad de su dimensión social. 


\section{Conclusiones}

El espacio urbano ha ocupado una posición central en las configuraciones discursivas de la prensa riocuartense a lo largo del siglo XX. Frente a las transformaciones de la ciudad, los diarios recuperaron los referentes del desorden y los organizaron en un espacio en el que se describió la ruptura de la norma. En sus páginas, la identificación de los aspectos considerados problemáticos ofreció la peculiaridad a las concepciones del orden que se manifestaron, al saber periodístico sobre la ciudad.

$\mathrm{Al}$ detenernos en ciertos momentos de la historia de Río Cuarto observamos que la presencia de estas enunciaciones se encontró naturalizada en función de determinados principios, a través de los cuales se definió lo esperable. Nuestra intención no estuvo orientada a identificar aquello que esas concepciones ocultan o la manera en que se fueron perfeccionando con el paso del tiempo. La tarea pretendió indicar que las concepciones de orden urbano y de las emergencias sociales son, en cada momento, una construcción. Identificar la manera en que el clima de la época se hizo presente en esas configuraciones fue una forma de problematizar las características de esas visibilidades y de reconocer su complejidad.

Un rasgo distintivo del saber que la prensa genera sobre la ciudad hace referencia a que a través de las definiciones que los tratamientos infor- mativos realizan sobre las emergencias sociales se refuerza una concepción de orden, sostenida por diferentes principios rectores. Al momento de señalar aquello que se constituye como "anormal", no deseado o impensable se confirma la aceptabilidad de aquello que se considera "normal", de aquello que en el clima de la época se cree que es el "orden natural". Los abordajes mediáticos realizados sobre las emergencias sociales, de esta forma, resultan reveladores con relación a lo que dejan ver respecto de las definiciones dominantes. Los tratamientos informativos dan cuenta de una concepción de orden que hasta el mismo desorden insinúa.

A través del recorrido realizado por los abordajes mediáticos pertenecientes a distintas etapas del siglo $\mathrm{XX}$, hemos observado que nociones como progreso, modernidad, crecimiento y urbanidad constituyeron tópicos a través de los cuales se definieron las concepciones sobre el orden urbano. A partir de estas imágenes la prensa se encargó de definir un modelo de ciudad. La activación de estos principios se vio movilizada por diferentes campos del saber, por lo que hemos visto variar sus referentes y los mecanismos implementados para abordar aquellos aspectos que los contradijeron o pusieron en duda.

Este planteo abre interrogantes al momento de analizar la prensa en virtud de los intereses a los que parece asociarse, ya que pone en discusión cuestiones profundas respecto de los modelos de organización social que 
priman en distintas épocas. Estas cuestiones parecen tener una incidencia peculiar en las concepciones de orden que subyacen en las configuraciones periodísticas. En este sentido, las imágenes de la ciudad y las emergencias sociales resultan consecuencias del modo en que se dispone ese orden social en los tratamientos informativos. Observamos, por ejemplo, que el protagonismo del Estado o del mercado en esa configuración ofrece un elemento valioso para analizar transformaciones cualitativas en la práctica periodística. Es en este marco que señalamos que no debemos abstraer el funcionamiento de la prensa de su encarnación en un particular estado de sociedad.

El abordaje de las construcciones mediáticas se presenta complejo, sobre todo si incorporamos el funcionamiento de los medios de comunicación como un dato ineludible de la cultura. Pretendimos cuestionar el carácter natural de esas configuraciones discursivas y preguntar qué fue lo que las hizo posible. Las respuestas no podían ser encontradas en la inmanencia de los discursos periodísticos. El clima de la época nos permitió problematizar el carácter construido de estas concepciones que, aunque se presenten naturales, están más bien naturalizadas.

\section{Referencias}

Alonso, P. (2003). Construcciones impresas, panfletos, diarios y revistas en la formación de los estados nacionales en
América Latina, 1820-1920. Buenos Aires: Fondo de Cultura Económica. Angenot, M. (2010). El discurso social. Los límites históricos de lo pensable y lo decible. Buenos Aires: Siglo XXI.

Blanco, A. (2006). Razón y modernidad. Gino Germani y la sociología en la Argentina. Buenos Aires: Siglo Veintiuno Editores.

Bauman, Z. (1996). Modernidad y ambivalencia. En J. Beriai (Comp.), Las consecuencias perversas de la modernidad. Modernidad, contingencia y riesgo. Barcelona: Anthropos.

Brunetti, P. (2006). Relatos de prensa: La crónica policial en los diarios cordobeses de comienzos de siglo XX (1900-1914). Córdoba: Editorial de la Facultad de Filosofía y Humanidades.

Bunge, A. (1940). Una nueva Argentina. Buenos Aires: Guillermo Kraft.

Caimari, L. (2004). Apenas un delincuente. Crimen, castigo y cultura en la Argentina, 1880-1955. Buenos Aires: Siglo Veintiuno Editores.

Castoriadis, C. (2007). La institución imaginaria de la sociedad. Buenos Aires: Tusquets Editores.

Demarchi, P. (2010). La actividad rurbana en la prensa local. En G. Cimadevilla y E. Carniglia (Coords.), Relatos sobre la rurbanidad. Río Cuarto: Universidad Nacional de Río Cuarto.

Foucault, M. (2007). La arqueología del saber. (2. ${ }^{a}$ ed.). Buenos Aires: Siglo Veintiuno.

Hall, S. (2010). Sin garantías. Ecuador: Envión Editores. 
Kusch, R. (1999). América profunda. Buenos Aires: Biblos.

Mallimaci, F. (2007). Los derechos humanos y la ciudadanía como matriz de análisis social. En S. Torrado, Población y bienestar en la Argentina del primero al segundo centenario. Una historia social del siglo XX. Tomo I. Buenos Aires: Edhasa.

Marocco, B. (2002). Prostitutas, jugadores, pobres y vagos en los discursos periodísticos. Porto Alegre-siglo XIX. Memoria para optar al grado de doctora, Departamento de Periodismo y Ciencias de la Comunicación, Universidad Autónoma de Barcelona, España.

Martín Barbero, J. (1978). Comunicación masiva: discurso y poder. Quito: Época.
Martínez Estrada, E. (2001). La cabe$z a$ de Goliat. Microscopía de Buenos Aires. Barcelona: Losada.

Novick, S. (1992). Política y población. Buenos Aires: Centro Editor de América Latina.

Romero, J. (1998). El desarrollo de las ideas en la sociedad argentina del siglo XX. Buenos Aires: AZ Editora.

Saítta, S. (1998). Regueros de tinta. El diario Crítica en la década de 1920. Buenos Aires: Editorial Sudamericana.

Suriano, J. (2005). Introducción: Una Argentina diferente. Nueva historia argentina. Dictadura y democracia (1976-2001). Buenos Aires: Editorial Sudamericana.

Williams, R. (1997). Marxismo y literatura. Barcelona: Península. 